\title{
Quality Costing: An Efficient Tool for Quality Improvement Measurement
}

\author{
Rathindra Nath De \\ Mechanical Engineering Department \\ Bengal Engineering and Science University, Shibpur \\ Howrah - 711103, West Bengal, India
}

\begin{abstract}
Sound economy and assured profitability of an organization entirely depend upon effective control of nonquality costs generated in the organization. Through simple economic model with parato and cause effect analysis of different elements of quality costs, e.g. Prevention, Appraisal costs conformance costs and internal and external failure costs - non conformance costs, total quality costs can be controlled resulting considerable savings. This paper discusses how quality has an impact on the costs of goods and services in an organization and "Return on Investment (ROI)" is linked with "Return on Quality (ROQ)". In the interest of customers and minimizing national loss due to proof quality of products and services, it should be obligatory for organizations to correctly report "Quality costs" in their annual reports like Balance Sheets and Profit and Loss Accounts.
\end{abstract}

\section{Introduction}

We have to properly identify and measure the costs associated with non-quality in any organization for basic three reasons: to quantify the size of quality problem, to help in satisfying a quality improvement effort and to guide the development of that effort, and to track progress in improvement activities. In any organization, all business activities and programmes are finally decided on the basis of their relative capabilities for contribution to profit. Knowledge of quality costs helps executives to justify the investment in quality improvement programme and assists them in monitoring the effectiveness of the efforts made. Quality costing expresses an organization's quality performance in the language of "Money" which is well appreciated by the board of management and stakeholders operators and line supervisors are also found to react positively when nonconformance data, in addition to the normally expressed measure of numbers and percentages, are presented in monetary terms. This happens when they have the opportunity to compare the costs of non-conformance with their salaries. The organizational goal is "Total Quality Management" and the process of quality improvement is the means of reaching this goal. It is important for an organization to understand that in today's markets customers' requirements are becoming more rigorous and at the same time it is likely that their competition will also be increasing. Consequently there is a need for the process of quality improvement to be continual and total. TQM should always be referred to as a process not a programme. Committing huge expenditure in quality improvement activities without some measure of its cost - effectiveness can be considered a blind act of faith and is contrary to the way in which Western business operate. In Japanese business organizations investment in quality improvement initiatives over a long period of time without thought of immediate benefits appears to be accepted without questions by senior managers, stakeholders and financial institutions. In addition to the quality of product and service, organizational need to be competitive on cost and delivery. This is termed as "QCD". If the organizations are to survive in their respective business in global competitive market, they are bound to achieve substantial cost reduction for their operations. In many instances quality-related costs are a major potential source of the necessary savings. Quality costing is one of several tools and techniques, which can assist companies with improving quality of product and service. It is also important that reducing the level of quality costs should not be the main reason for an organization starting a process of quality improvement. Along the TQM journey for an organization as a first step quality costing may be considered useful. For becoming a total quality organization it is necessary to have first - hand experience on the benefits of measuring quality costs. Hence, a number of world - class quality organizations employed measuring quality costs which is an indicator for their internal quality performance.

\section{Costs of Quality}

There is no uniform view of what is meant by quality costs and what should be included under the umbrella of costs of quality. Definitions are key feature in quality costing. The definition of what constitutes quality costs is by no means straightforward and there are many grey areas where good production and operation practices overlap with quality related activities. Ideas of what constitutes quality costs have been changing rapidly in recent years. Only a few years ago the costs of quality were perceived as the cost of running the quality assurance department, plus costs of scraps, rework and warranty, it is now widely accepted that they are hidden 
costs incurred in design, implementation, operation and maintenance of an organization's quality system, the cost of organizational resources committed to the process of continuous quality improvement and service failures. System failures can result in obsolescent stocks, work, scrap, rectification work, late deliveries, additional transportation costs, poor service, and non - conforming products. Product and / or service failures result in warranty, guarantee and product liability claims, complaint administration and investigation, product recall, additional customer service costs, and loss of customer goodwill. So quality - related costs generate from a range of activities and involve all the departments in an organization. These departments mainly are:
a) Sales and marketing.
b) Design, research and development.
e) Manufacturing / operations
c) Purchasing, storage and handling.
d) Production or operation planning and control.
f) Delivery, installation
g) Service
h) Finance and accounts.

\section{Background of Quality Costing}

Feigenbaum in mid 1950s identified quality costs consist of prevention, appraised and failure costs in his seminal paper. Until then all the earlier papers on quality mention only inspection, rework, repair and warranty cost i.e. the elements of appraised and failure categories of quality - related costs. In 1967 the American Society for quality control (ASQC) published "Quality Costs What and How" in which quality costs are defined only by category and by reference in 1970 and 1974, is still perhaps the most definitive work on the subject, even though it does not include all the cost elements which might be identified as being quality related in a total approach to the management of product and service quality. It takes the "What" concept and quality cost definitions from Feigenbaum's book "Total Quality Control", but adds sources for finding cost data and gives a lot of good advice on what to include, what to leave out, and specific warnings to be cautions in interpreting and using cost data. Other ASQC publications, which deal best with practical aspects on how to do quality costing, are "Guide for Reducing Quality Costs" and "Guide for Managing Supplier Quality Costs". The "Guide for Reducing Quality Costs" develops the uses of quality improvement projects and to the involvement and responsibilities of technical, marketing and purchasing functions in quality matters. It deals with identifications problem areas and analysis of quality costs. It makes specific recommendations on reducing failure and appraisal costs, prevention of quality costs, and measuring improvement. The idea of projecting failure and appraisal costs as desirable targets for cost reduction but regarding prevention as a cost - saving activity is a commendable one. Under the heading "Prevention of Quality Costs" are listed ways in which marketing, design, quality assurance, and indeed management, in general, can help to prevent appraisal and failure costs from arising. The Guide for managing supplier quality costs is an acknowledgement of the fact that companies purchase some of their quality problems. Most of the business organizations are now devoting considerable resources in developing their relationships with supplier communities and working more closely with them on quality improvement initiatives. This guide booklet refers to the methods of vendor control, the visible and hidden quality costs related to vendor control, and methods of applications of quality cost to Vendor Control. Here two themes are pursued, identifying and attacking vendor - related problems through joint perfects with the vendor and motivating the vendor to adopt his own quality cost programme.

BS6143 - 1981 "Guide to the Determination and use of Quality Related Costs" provides the guidance on the operation of a quality costs system within a manufacturing organization. But it does not reflect accurately the incidence and distribution of costs in manufacturing industry and non - manufacturing operations as encountered the researches of Dr. Jim Plunkett and Dr. B. G. Dale during publication of their book "Quality Costing". The emphasis in BS6143 - 1981 reflects the magnitude of quality activities rather than quality related costs. This standard highlights in more details for quality costs related to prevention activities which is normally $2 \%$ of quality costs whereas internal failure costs which contributes to $63 \%$ of quality costs are not analyzed in details. This standard was technically revised and titled as "Guided to the Economics of Quality" Part $1-1991$ and Part - 2 - 1990. To cater for non - manufacturing situations and for those organizations wishing to pursue an alternative approach to the prevention appraisal - failure (PAF) model the first part of the guide comprises a process cost modeling approach. The second part is a revised version of the classical PAF model. Manufacturing industries primarily used quality costing but now it is used for most of the public sectors and service - related organizations like British Airways Technical Workshops responsible for the overhaul and repair of items removed from aircraft, John Russell (Frogmouth), a transportation and Warehousing company and National Westminster Bank.

\section{Importance of Quality Costs}

Failure costs: Firstly these costs are very large. In 1978 the estimated quality costs was $10 \%$ (£ 10,000 million) of UK's GNP (Gross National Product). The findings in 1985 showed that some $10 \%$ to $20 \%$ of an organization's total sales value is accounted for by quality - related costs and, using the figure of $10 \%$, it was estimated that UK manufacturing industry could save up to $£ 6$ billion each year that quality - related costs 
depending on the type of industry commonly range from $5 \%$ to $25 \%$ of company annual sales turnover.Secondly, $95 \%$ of the quality costs is usually expended on appraisal and failure. These expenses are not at all for value added activities related to product or service, and at least the can be avoided or reduced by eliminating causes of non - conformance resulting substantial reductions in appraisal costs. The savings are directly added to the profit of the organizations. Thirdly, unnecessary and avoidable costs make goods and services more expensive. This in turn affects competitiveness and, ultimately, wages, salaries and standards of living. Fourthly, despite the fact that the quality - related costs are large, and that a substantial proportion of them are avoidable, it is apparent that the costs and economics of many quality - related activities, are not known by companies. Such a state of affairs is surely indefensible in any well - run business.

\section{Reason for Measuring Costs of Quality}

The measurement of costs of quality allows quality - related activities to be expressed in the language of top management i.e. money. This, in turn, allows quality to be treated as a business parameters along with line functions such as marketing, research and development, and production / operations / services. Drawing quality costs into business arena helps to emphasize the importance of product and service quality to corporate health and will help to influence employee behaviour and attitudes at all levels in the organizations towards TQM and continual quality improvement. Quality costs measurement focuses attention on areas of high expenditure and identifies potential cost - reduction opportunities. It allows measurement of performance and provides a basis for internal comparison between products, services, Processes and departments. Measurement of quality related costs also reveals quirks and anomalies in cost allocation and standards which may remain undetected by the more commonly used production / operation and labour - based analyses. Measurement also can obviate the dumping of embarrassing after - sales costs under quality - related headings. Finally, quality costs measurement is the first step towards control of costs and quality improvement activities. Normally manufacturing organizes categorize costs of quality as:

- Prevention Costs

- Appraisal Costs

- Internal Failure Costs

- External Failure Costs

\section{Objectives of Collection and Measuring Costs of Quality}

There is little point in collecting costs of quality just to see what they may reveal. If the purpose is to set a percentage cost - reduction target on the company's total quality - related costs, it will be necessary to identify and measure all the contributing cost elements in order to be sure that costs are reduced and not simply transferred elsewhere. Before setting up a quality cost collection system, it is advisable to examine the potential for charge of a cost element in both absolute and relative terms. The inclusion of fixed or immutable costs also has the effect of reducing the sensitivity of costs to performance - improving changes on the other hand, if costs are not being monitored, how does one know that they are not going to change? An acceptable compromise is to carryout occasional total cost exercises but to monitor regularly and emphasize only those costs, which are likely to change with improvement activities. The basis of the argument supporting this view is that it is unnecessary to know all the costs to be sure, for example, that quality costs are decreasing.

\section{Method of Collection of Quality Costs}

The aspect of measuring and collecting quality costs is basically a quality cost reduction exercise. The costs collectors have to develop their own list of quality costs elements from company specific experience. The cost collector has to identify potential elements of cost, which are relevant to their organization. Then it is required to quantify the elements and finally is to cost the elements. The usual approach is for a quality assurance specialist, in conjunction with other appropriate company personnel, to take responsibility for identifying the elements and provide appropriate quantitative data relating to each element. The accountant will put costs on the elements, which have been identified. It is helpful if the quality assurance and technical personnel liaise with the accountant during this activity.

Method 1 -After an introduction by the company's chief executive officer, confirming their commitment to quality costing as an essential aspect of TQM, a quality assurance specialist will give a briefing on what are costs of quality, their uses, the concept of quality cost categories and elements, examples of specific cost elements in the organization, why the organization is setting out to identify quality costs, and the methodology which is to be employed to identify, collect and measure the costs to all departmental heads and members of the senior management team. In order to help managers for distinguishing quality parameters into types of prevention, appraisal and failure activities, some organizations use a questionnaire relating to the various activities of the organizations. This assists in developing a common understanding within the organization of the three types of quality costs categories. Some organizations take the view that in the initial stages of the quality costing exercise, the emphasis is on just identifying the costs of failure and appraisal activities. To facilitate identification of quality costs elements, the Quality Management tools and techniques, such as brainstorming, 
cause and effect analysis are useful for each department using a team approach. Once the quality costs elements are identified for each department, departmental head in discussion with quality assurance specialist refine each department's list of quality cost elements. After the elements have been agreed the next step is for each department to determine the amount of time they are spending on each cost element, which has been identified. During this activity the cost of wastage on items such as paper, materials, forms, etc., is also identified. The quality assurance specialists assist the departments in the task. The accountant then works with each departmental manager and with quality assurance specialists in putting a cost on each element identified.

Method 2 - Each department is treated as a process using the computer aided manufacturing integrated programme definition method. The process modeling method employs an activity box with inputs, outputs, control and mechanisms.

\section{Uses of Quality Costs}

There is no point in collecting quality costs information if it is not to be used. The uses of quality costs are grouped into three broad categories.

a) To improve product and service quality as a business parameter.

b) Facilitating performance measures and improvement.

c) Provide the means for planning and controlling future quality costs.

A Case Study: As per BS 6143: 1981 quality costs categorization costs are put on a company's operations.

\section{Prevention costs}

$\mathrm{A}_{1}-$ Costs related to Quality engineering and Process engineering - Planning the quality system and translating product design and customer quality requirements into manufacturing quality controls of materials, processes and products and those costs associated with implementing and maintaining quality plans and procedures. Estimated time $30 \%$ for quality engineering and $30 \%$ for process engineering of a senior person of quality control having yearly employment cost of Rs.1,20,000/-.

$\mathrm{A}_{2}$ - Costs of design and development of quality measurement and control equipment. The cost sources are estimated as $5 \%$ each of a senior shaft of quality control department and production engineering departments, costs related to research and development work and charges for research materials

$\mathrm{A}_{3}$ - Quality planning by functions other than quality control dept., which is not applicable in most companies.

$\mathrm{A}_{4}-$ Calibration and maintenance of production equipment used to evaluate quality. The costs are estimated as at half a man - day per month.

$\mathrm{A}_{5}$ - Maintenance and calibration of test and inspection equipment. Sources of cost data for this element are (1) the financial code for indirect materials - inspection equipment; (2) invoices for calibration services from outside the company; (3) staff time input, estimated as being $5 \%$ of a senior person of quality control.

$\mathrm{A}_{6}$ - Supplier assurance - The staff time input from quality control department is estimated to be $8 \%$ of a senior.

$\mathrm{A}_{7}$ - Quality Training - The costs of this element are wholly within the quality control department and the staff time is estimated as $2 \%$ of a senior staff.

$\mathrm{A}_{8}$ - Administration, audit, improvement - costs of travel, telephones, post, printing, etc. are administration cost including depreciation costs of the capital assets of quality control department. Auditing and improvement costs, mostly incurred within the quality control department, are estimated as $15 \%$ of a senior person's time.

Table 1: The prevention costs and findings are summarized

\begin{tabular}{|l|l|l|}
\hline \multicolumn{1}{|c|}{ Cost elements } & Annual costs (Rs.) & \multicolumn{1}{c|}{ Source } \\
\hline $\mathrm{A}_{1}$ & 72,000 & Estimated time \\
\hline $\mathrm{A}_{2}$ & 12,000 & Estimated time \\
\hline $\mathrm{A}_{3}$ & Nil & - \\
\hline $\mathrm{A}_{4}$ & 3,000 & Estimated time \\
\hline & 24,000 & Materials \\
\hline $\mathrm{A}_{5}$ & 30,000 & Service \\
\hline $\mathrm{A}_{6}$ & 6,000 & Estimated time \\
\hline $\mathrm{A}_{7}$ & 9,600 & Estimated time \\
\hline $\mathrm{A}_{8}$ & 2,400 & Estimated time \\
\hline & 18,000 & Estimated time \\
\hline Total & 48,000 & Capital depreciation \\
\hline Annual sales Turn over & $2,25,000$ & \\
\hline$\%$ Prevention costs of Annual Sales Turn over 0.064 & \\
\hline
\end{tabular}




\section{Appraisal costs - costs of assessing the quality achieved}

$\mathrm{B}_{1}$ - Laboratory acceptance testing costs for purchase production materials.

These are the costs of tests to evaluate the quality of purchased materials which become part of the final product or that are consumed during production operations. Costs estimated as Rs.2,00,000/- per year.

$\mathrm{B}_{2}-$ Costs related to inspection and test including receiving inspection.

This element covers the inspection activity from within the quality control department. It is the cost of 8 full - time inspectors, plus $70 \%$ of the time of a supervising foreman / manager.

$\mathrm{B}_{3}-\mathrm{In}$ - process inspection by personnel other than inspectors. In this company engineering manufacture operators are frequently required to carry out inspections as part of their normal work. There are nine skilled workers employed full time for this job. Annual cost is Rs.49,50,000 without considering overhead costs.

$\mathrm{B}_{4}-$ Set-up for inspection and test.

This is the payroll cost of setting up equipment or products for inspection and function testing. This time is booked in the machine shop for set-up and test of machines. The cost is not considered as quality related cost.

$\mathrm{B}_{5}$ - Inspection and test materials (i.e. material consumed or destroyed in the control of quality) - Most of the costs have been included under element $\mathrm{A}_{5}$. Material usage arising from destructive test is included in company's scrap costs. Hence costs are not considered.

$\mathrm{B}_{6}-$ Product quality audits.

The estimated cost is $2 \%$ time of a manager in the quality control department.

$\mathrm{B}_{7}-$ Review of test and inspection data.

This cost is not applicable for the said company.

$\mathrm{B}_{8}-$ Field (on - site) performance testing - costs incurred in testing for product acceptance on customers' premises. The estimated time is $2 \%$ of a manager in the quality control department.

$\mathrm{B}_{9}$ - Internal testing and release - The cost of setting up and in - house testing of the complete product for customer acceptance. In this company such work is normally covered under $\mathrm{B}_{2}$ and $\mathrm{B}_{3}$. Occasionally special arrangements may be made for a customer to witness tests. The level of staff involvement in this activity is estimated to be $2 \%$ time of quality control manager.

B10 - Evaluation of site material (field stock) and spare parts - the costs of evaluation, testing or inspection of site material, resulting from engineering changes, storage conditions etc.

Since most of the company's production is made for stock by distributors and users there is often a considerable delay between manufacture and the product going into service. Hence problems arise from deterioration during storage, change, changes to specifications, etc. It is estimated that attention to these problems takes up to $5 \%$ of quality control manager's time.

B11 - Data processing inspection and test reports - The costs incurred in accumulating and processing test and inspection data received from service centers as well as manufacturing operation, used in evaluation work within quality control department. It occupies an estimated $20 \%$ of the time of quality control manager.

Table 2: The results of the examination of appraisal costs are summarized in the following table:

\begin{tabular}{|l|l|l|}
\hline \multicolumn{1}{|c|}{ Cost elements } & Annual costs (Rs.) & \multicolumn{1}{c|}{ Source } \\
\hline $\mathrm{B}_{1}$ & $2,00,000$ & Account \\
\hline $\mathrm{B}_{2}$ & $56,00,000$ & Employment cost of 10 full time inspectors \\
\hline & $4,90,000$ & Estimate part - time quality control manager \\
\hline $\mathrm{B}_{3}$ & $49,50,000$ & 9 full time test and repair men's employment costs \\
\hline $\mathrm{B}_{4}$ & - & Not applicable \\
\hline $\mathrm{B}_{5}$ & - & Included under A5 and C1 \\
\hline $\mathrm{B}_{6}$ & 14,000 & Estimated time \\
\hline $\mathrm{B}_{7}$ & - & Not applicable \\
\hline $\mathrm{B}_{8}$ & 14,000 & Estimated time \\
\hline $\mathrm{B}_{9}$ & 14,000 & Estimated time \\
\hline $\mathrm{B}_{10}$ & 35,000 & Estimated time \\
\hline $\mathrm{B}_{11}$ & 14,000 & Estimated time \\
\hline Total & $111,31,000$ & \\
\hline Annual Turn over & $35,00,00,000$ & \\
\hline $\begin{array}{l}\text { Appraisal costs \% of Annual } \\
\text { Turn over }\end{array}$ & 3.18 & \\
\hline
\end{tabular}

\section{Internal failure costs}

These are the costs arising of failure to achieve specified quality within the organization (before transfer ownership to the customer). The major items of costs are scrap and rework. 
$\mathrm{C}_{1}$ - All scraps losses incurred I the course of meeting quality requirements. This element includes only that scrap arising of manufacturer's fault.

These costs are generated from inspection / rejection report and standard costs. They comprise the cost of materials and direct labour to the point of scraping. The scrap arises mainly from machine set-up and off cuts is also considered as an expensive source of scrap.

The income from selling of scrap is not deducted from the costs of scrapping products since the type and quantity of scrap sold at a particular time may bear no relationship to the current output.

Staff time input from the quality control department is estimated as $10 \%$ of quality control manager's time and there is some input from the accounts department in preparing cost data.

$\mathrm{C}_{2}$ - Rework and repair - The cost incurred in meeting quality requirements where material can be restored for use. The direct labour costs working on nonconforming materials are charged.

$\mathrm{C}_{3}$ - Trouble shooting or defect / failure analysis (to determine causes).

This work is carried out within quality control department and is estimated to take $10 \%$ of the time of quality manager.

$\mathrm{C}_{4}$ - Reinspection, retesting of products, which had failed previously. The costs incurred under $\mathrm{B}_{3}$ and $\mathrm{C}_{2}$ above, the involvement of test and repair workers in the production process complicates apportionment in this heading. Reinspection and retesting of rerouted rework is not identified separately from first inspection and tests. Because initial failure rates can be as high as $50 \%$ (although with easily repairable minor defects) the costs of the activities under this element could be fairly large.

$\mathrm{C}_{5}$ - Scrap and rework; fault of supplier's downtime.

Suppliers are expected to reimburse the full purchase price of any supplies, which are unusable owing to supplier's fault. Any other costs incurred up to the point of scrapping are not recovered on the matter of rework, it is either carried out by the supplier or by the company at the supplier's expense on some occasions attempted rework of faulty supplies may cause some lost time, materials or throughput. The costs of which are to be considered in this element.

$\mathrm{C}_{6}-$ Modifications, permits and concessions - the costs of time spent reviewing products, designs and specifications - usually from the engineering department or occasionally from customers. There is a substantial monthly design charge, much of which could be related to design changes. The input from the quality control department is estimated to be $10 \%$ of the time of manager quality control.

$\mathrm{C}_{7}$ - Downgrading - Most of the companies do not sell their products as "Seconds" at a reduced price. Hence this cost is not considered.

Table 3: The internal failure costs

\begin{tabular}{|l|l|l|}
\hline \multicolumn{1}{|c|}{ Cost elements } & \multicolumn{1}{c|}{ Annual costs (Rs.) } & \multicolumn{1}{c|}{ Source } \\
\hline $\mathrm{C}_{1}$ & $10,79,1200$ & Account \\
\hline $\mathrm{C}_{2}$ & $6,06,1160$ & Defective \\
\hline & $1,05,0000$ & Material hours \\
\hline & 70,000 & Estimated time \\
\hline $\mathrm{C}_{3}$ & 70,000 & Estimated time \\
\hline $\mathrm{C}_{4}$ & - & Included under $\mathrm{B}_{3}$ \\
\hline & Negligible & - \\
\hline $\mathrm{C}_{5}$ & 70,000 & Estimated time \\
\hline $\mathrm{C}_{6}$ & $23,70,000$ & Engineering department \\
\hline $\mathrm{C}_{7}$ & - & Not applicable \\
\hline Total & $2,04,22,360$ & \\
\hline Annual Turn over & $35,00,00,000$ & \\
\hline Internal failure costs \% of Annual Turn over & 5.835 & \\
\hline
\end{tabular}

\section{External failure costs}

These are defined as the costs arising outside the manufacturing organization of the failure to achieve the quality specified (after transfer of ownership to the customer). Interpretation of the definition is not as straightforward as it appears, in as much that (1) the point of transfer of ownership is not unequivocal defined; (2) in the case of the company's products, the warranty period may not be initiated until several years after the sale of the product to the customer.

$\mathrm{D}_{1}$ - Companies administration - the costs of administration of these complaints which are due to quality defects.

Complaints being handled by the manufacturing company (as distinct from the distribution service and agency outlets) are dealt with wholly within quality control department. It is estimated that the time spent on such matters is $5 \%$ of the time of a quality manager.

$\mathrm{D}_{2}$ - Product or consumer service; product liability. 
Costs arising within the manufacturing company are likely to be included under $\mathrm{D}_{1}$ above.

$\mathrm{D}_{3}$ - Handling and accounting of products rejected or recalled.

Costs of these are not measured or estimated. They are probably negligible.

$\mathrm{D}_{4}-$ Returned material repair.

Repair work is carried out under one cost centre and corers (1) work which is chargeable back to the customer; (2) work done under warranty; (3) repairs carried out free of charge. It is important here to distinguish between (2) and (3). Work done under warranty is work relating to products which have failed in service whilst under warranty (other warranty costs are included under $\mathrm{D}_{5}$ by virtue of work carried out by retail service outlets). Work done free of charge on products returned by customer is work relating to products which failed on test or were damaged on receipt or corroded, etc. It is this latter cost which is to be collected under this element. It is defined in the accounts as "Company Liability". The quality control department staff effort input to this activity is inseparable from that going into element $\mathrm{D}_{5}$.

$\mathrm{D}_{5}$ - Warranty replacement

The costs of replacing products, which have failed within, warranty period.

Charges arise from several different sources: (1) payment made to the service centres for repairs carried out under warranty; (2) replacement products issued free of charge to service centres or customers in exchange for failed products which are repairable; and (3) staff time input dealing with warranty claims and payments $65 \%$ of a quality engineer's time. Though it is simple in principle, but the actual method of achieving the objective of satisfying customers may render the collection of costs different. Some customers deal directly with the factory and faulty product may be repaired and returned to the customer at a certain cost, or they may be replace in the stock by stripping and refurbishing the returned unit, but at a different cost. Service centres are recompensed at agreed rates for warranty repair work, but the same rates do not appear to apply to similar repairs carried out at the factory. Replacement units issued by service centres when a faulty unit is irrepairable are billed at the service centre stock valuation, which of course, is far higher than the factory issue price. Free - of - charge replacements of products found to be faulty before going into service are more straightforward but the valuation and crediting of the returned damaged product is unclear.

Table 4: The external failure costs

\begin{tabular}{|l|l|l|}
\hline \multicolumn{1}{|c|}{ Cost elements } & Annual costs (Rs.) & \multicolumn{1}{c|}{ Source } \\
\hline $\mathrm{D}_{1}$ & 35,000 & Estimated time \\
\hline $\mathrm{D}_{2}$ & - & Covered in $\mathrm{D}_{1}$ and $\mathrm{D}_{5}$ \\
\hline $\mathrm{D}_{3}$ & - & Included in $\mathrm{D}_{4}$ \\
\hline $\mathrm{D}_{4}$ & $26,37,880$ & Accounts \\
\hline $\mathrm{D}_{5}$ & $15,60,440$ & Accounts \\
\hline & $4,55,000$ & Estimated time \\
\hline Total & $46,88,320$ & \\
\hline Annual Turn over & $35,00,00,000$ & \\
\hline External failure costs \% of Annual Turn over & 1.34 & \\
\hline
\end{tabular}

\section{Discussions of Findings}

It is intended to discuss each category of costs in the broader context of the cost collection exercise as a whole. (a) Prevention costs - In a small company it is necessary to record or estimate the proportions of time spent by personnel on each prevention activity in order to obtain a prevention cost analysis. In the present instance some $55 \%$ of the prevention cost is derived from estimated time coupled with an average employment cost.

(b) Clearly the costs of inspection and testing are far greater than all the other appraisal costs put together. Indeed some of the elements listed in BS 6143 attract no costs at all, and several others which together account for less than $10 \%$ of a manager's time might usefully be combined. In fact, apart from charges incurred for laboratory acceptances testing, the appraisal costs are the employment costs of ten inspectors, nine test and repairmen and one foreman/manager from the quality control department. Problems of estimating apportionment of a foreman/manager's time are rather more straightforward under this category because $90 \%$ of it is divided between only two elements. Nonetheless it is felt that it could be beneficial to record board uses of time as suggested earlier. Under this category two problems of definition of quality-related costs arise. The first is whether all or part of the activities of test and repair workers should be classified as being quality related, and the second is whether quality-related direct work should attract overheads for the purpose of measuring qualityrelated costs. The effects on quality cost distributions and ratios of omitting this cost are shown in Table 6.6. The effects of splitting the cost between production and quality, or between quality cost categories, have not been evaluated. The second problem, whether direct worker costs should attract overheads when measuring quality-related costs, is fundamental to the whole exercise of quality costing. The high overheads, which exist in 
manufacturing industry, can grossly distort the level and distribution of quality costs. If overheads are included, the costs of those elements involving direct workers are going to be grossly inflated in comparison with those involving indirect workers.

(c) Scrap and rework charges together with design changes account for almost the whole of the cost under this category. Although the system for collecting costs of scrap is well established, other costs in this category were difficult to obtain. The problem of overheads arises again, and whilst it is conceded that it is entirely appropriate for overheads to be added to direct labour charges for the purpose of stock valuations and records, it is again contended that it is not appropriate for the purpose of collecting quality-related costs. The problem arises only because of the practice of recovering overheads on a direct labour basis. If a basis of, say, units of saleable products was used, there would not be a problem. A noticeable feature of scrap reports is the significantly large weights of non-ferrous scrap (1 tonne per month) accruing under the heading 'natural wastage' which arises mainly from material used during set-up and from off cuts or surpluses from stamping operations. Such scrap is a production materials loss. Its value is not a quality-related cost and care must be taken that it is not counted as such. The approval of BS 6143 of the practice of deducting income from sales of scrap from scrap costs is surprising for the reasons already given under $\mathrm{C} 1$ earlier. The definition of rework and repair costs is complicated by the test and repair situation as discussed earlier. Leaving aside that complication, even in those cases where the definitions and procedures to procure rework costs appear to be straightforward; difficulty was experienced in obtaining them. Similarly no firm data were available for the costs of modifications, concessions and the general impact of design engineering on quality-related costs. In the context of internal failure costs it is interesting to speculate whether the true economics surrounding the scrap or rework decision are known for each product under different conditions of output rate, urgency of delivery, materials supply, etc., or whether the decisions are really made in the light of engineering knowledge and experience.

(d) The major costs incurred are for repair of products, which have been returned by customers because they were found to be faulty before being put into service, and replacement of products, which have failed in service during the warranty period. Although superficially it should be a simple matter to determine the magnitude of these costs, in practices. The systems are described under D4 and D5. Examples of the complications, which arise in ascertaining quality costs, are replacement of a defective unit from stock and replenishing the stock by refurbishing (as distinct from repairing) the faulty unit, and the obscuration of in-house warranty work carried out in the repair section of the factory. However, the figures quoted in Table 6.5 are supplied by the accounts department and have, presumably, been properly disentangled.

\section{Conclusion}

The only presentation and uses of quality-related costs in company 1 are the monthly reporting of the quality control department costs for budgetary control purposes and reporting of gross costs of scrap and warranty in management account. Although ratios are used as performance indicators in some aspects of the business, gross values are preferred. Quality costs do not feature in any of the ratios used. These typically involve measures of labour, sales and manufacturing cost. Costs do not appear to feature specifically in the day-to-day decisions about quality matters though it must be said that there is a very cost conscious atmosphere about the factory. On the other hand, dealing with warranty claims is a very cost-oriented activity, the basic documentation for which is a list of product applications, normal warranty limits, exceptions, warranty reimbursement costs, and agreed labour rates for agencies and service centers.

\section{References}

1. BS 6143 (1981) The Determination and Use of Quality-Related Costs, British Standards Institution, London.

2. ASQC Quality Costs Committee (1974) Quality Costs - What and How, American Society for Quality Control, Milwaukee WI.

3. BS 6143: Part 2 (1990) Guide to the Economics of Quality: Prevention, Appraisal and Failure Model, British Standards Institution, London.

4. Anon (1977) Quality cost survey. Quality, 20 - 2. 